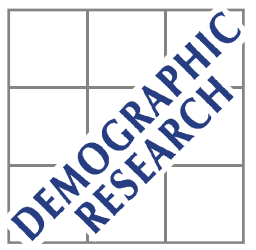

Demographic Research a free, expedited, online journal of peer-reviewed research and commentary in the population sciences published by the Max Planck Institute for Demographic Research Konrad-Zuse Str. 1, D-18057 Rostock · GERMANY www.demographic-research.org

DEMOGRAPHIC RESEARCH

VOLUME 22, ARTICLE 10, PAGES 211-236

PUBLISHED 12 FEBRUARY 2010

http://www.demographic-research.org/Volumes/Vol22/10/

DOI: $10.4054 /$ DemRes.2010.22.10

Research Article

Modeling fertility curves in Africa

Ezra Gayawan

Samson B. Adebayo

Reuben A. Ipinyomi

Benjamin A. Oyejola

(C) 2010 Ezra Gayawan et al.

This open-access work is published under the terms of the Creative Commons Attribution NonCommercial License 2.0 Germany, which permits use,

reproduction \& distribution in any medium for non-commercial purposes, provided the original author(s) and source are given credit.

See http:// creativecommons.org/licenses/by-nc/2.0/de/ 


\section{Table of Contents}

1 Introduction $\quad 212$

2 The pattern of age-specific fertility rate for African countries 213

$3 \quad$ Models for fertility schedules 216

$4 \quad$ The model $\quad 217$

$5 \quad$ Evaluation of the model $\quad 219$

$\begin{array}{lll}6 & \text { Conclusions } & 220\end{array}$

7 Acknowledgements 221

$\begin{array}{ll}\text { References } & 222\end{array}$

$\begin{array}{ll}\text { Appendix A } & 225\end{array}$

$\begin{array}{ll}\text { Appendix B } & 233\end{array}$ 


\title{
Modeling fertility curves in Africa
}

\author{
Ezra Gayawan ${ }^{1}$ \\ Samson B. Adebayo ${ }^{2}$ \\ Reuben A. Ipinyomi ${ }^{3}$ \\ Benjamin A. Oyejola ${ }^{4}$
}

\begin{abstract}
The modeling of fertility patterns is an essential method researchers use to understand world-wide population patterns. Various types of fertility models have been reported in the literature to capture the patterns specific to developed countries. While much effort has been put into reducing fertility rates in Africa, models which describe the fertility patterns have not been adequately described. This article presents a flexible parametric model that can adequately capture the varying patterns of the age-specific fertility curves of African countries. The model has parameters that are interpretable in terms of demographic indices. The performance of this model was compared with other commonly used models and Akaike's Information Criterion was used for selecting the model with best fit. The presented model was able to reproduce the empirical fertility data of 11 out of 15 countries better than the other models considered.
\end{abstract}

\footnotetext{
${ }^{1}$ Department of Mathematical Sciences, Redeemer's University, Redemption City, Nigeria. E-mail: ezrascribe@yahoo.com.

${ }^{2}$ Research and Evaluation Division, Society for Family Health, Abuja, Nigeria. E-mail: adebayo_sba@yahoo.com.

${ }^{3}$ Department of Statistics, University of Ilorin, Ilorin Nigeria. E-mail: ipinyomira@yahoo.co.uk.

${ }^{4}$ Department of Statistics, University of Ilorin, Ilorin Nigeria. E-mail: boyejola2003@yahoo.com.
} 


\section{Introduction}

Parametric and non parametric models have been reported to have useful applications in demographic research. Apart from being useful when creating hypothetical rate schedules in forecasting and projection, they also serve to condense complex data into smaller indices (Schmertmann 2003; Peristera and Kostaki 2007). Several models have; therefore, been proposed to model fertility as the major determinant (of the three demographic variables namely, fertility, mortality, and migration,); of the size and structure of any population. These models have been commonly created for the developed countries of the world and usually fit excellently the population they are intended to model (Hoem et al. 1981).

It is pertinent, however, to mention that though there are many fertility models in the literature, few have been specifically generated to describe age-specific fertility patterns in Africa; despite the fact that most governments of the sub Saharan African countries are targeting lower total fertility rates to meet the Millennium Development Goals (MDGs) (United Nations 2000). To make reaching these targets possible, a better understanding of the current pattern of age specific fertility rate (ASFR) of African countries is required. Mathematical models, when well constructed, can aid in this understanding as they provide better insight into some characteristics of the distributional pattern of fertility in Africa. The goal of any modeling exercise is to extract as much information as possible from available data and to provide an accurate representation of both the known and unknown aspects of the phenomenon being studied (Salomon and Murray 2001). Modeling fertility in Africa has also become necessary to enable a meaningful comparison of fertility across the countries in the region in the face of the current fertility transition. Already, fertility can be compared using a wide variety of existing conventional measures, summary indices, or averages that are commonly reported for fertility data. These include total fertility rate (TFR), general fertility rate, and the crude birth rate. Few comparisons, however, are made based upon the detailed distribution of the age-specific fertility curve. Not all information in the curve can be conveyed by these summary indices. There is still much to be described in terms of the variance, skew, kurtosis, and symmetry of fertility distributions for individual countries on the continent.

In this article, we propose a mathematical model for ASFR using the complementary error function (defined below). The proposed model is a flexible one that can capture various shapes of ASFR. It also provides a mathematical description of some fertility indices through its interpretable parameters. The efficacy of the model was determined by comparing its performance with other fertility models.

The age pattern of fertility in Africa is described in the next section. In Section 3, we provide a brief review of some existing models for fertility patterns and then 
propose our model in Section 4. The results of fitting our model as well as other models to the fertility data are presented in Section 5. This paper concludes with a discussion of the implications of our findings.

\section{The pattern of age-specific fertility rate for African countries}

African countries are numbered among those in the world with the highest fertility rates (Norville, Gomez, and Brown 2003). Several factors have contributed to these high levels of fertility. Some of these factors include high level of infant and child mortality, early and universal marriage; resulting in child bearing which begins early and continues for much of the reproductive life span. Additionally, the low use of contraceptives and the high value societies place on childbearing contributes to high fertility among the populations of African countries. As a result of the perceived high infant and child mortality, people have many children in the hope that some children will survive to carry on the family line. The institution of polygamy promotes competition among co-wives to have children; which also contributes to high fertility in many African countries. Furthermore, the traditionally high value placed on marriage ensures not only its universality, but also its occurrence early in life. The consequence is that child-bearing will start early and in most cases, continue until late in the reproductive lifespan. Caldwell (1980) asserted that one explanation for high fertility rates is that the lifestyle of most of the population in African countries is commonly rural and less industrialized than that of the rest of the world. This rural lifestyle encourages the population to engage predominately in subsistence farming, and as a result, to consider large family size as an asset.

Makinde-Adebusoye (2001) classified African countries into three categories based on their positions on a demographic transition continuum. Those countries classed as Category I are those that have fertility data supporting a demographic transition from high to much lower fertility levels. Countries that fall into this category include Cote D'Ivoire, Ghana, Nigeria, Kenya, Rwanda, Botswana, Zambia, Zimbabwe, Egypt, Morocco, and Tunisia. Countries in category II are those that have recorded a small decline in TFR. These countries are Benin, Mauritania, Senegal, Cameroon, Central Africa Republic, Malawi, Tanzania, and Swaziland.

Category III countries are those in which the fertility levels appear to have stabilized around a peak with TFR of approximately 6 or more. Countries in this category are Burkina Faso, Liberia, Mali, Togo, Burundi, Ethiopia, Madagascar, Mozambique, and Uganda. Others included in this category are Niger, Angola, and the Democratic Republic of Congo. It is worth noting that the above categorization is not exhaustive for all African countries. 
A plot of the ASFR for countries from each of the above categories reveals some differences in the age pattern of fertility among African countries. Figure 1 shows the five-year age pattern of fertility for Egypt, Cameroon, and Ethiopia (chosen from categories I, II, and III respectively). Some characteristics of African fertility pattern can be observed from Figure 1. The pattern for Egypt starts with a lower rate than those of the other two countries. It rises to reach the peak in the late twenties (age group 2529) before it starts dropping rapidly. Unlike Egypt, Cameroon's pattern starts with a relatively higher rate and peaks in the early twenties (age group 20-24). It does not demonstrate a rapid drop after the peak. In contrast to the other two countries, Ethiopia depicts a broad peak shape that extends from the early twenties to the early thirties before a rapid drop. Additionally, whereas the tail of the curve almost approximates zero in the early forties for Egypt, that of Ethiopia is still much higher at the same point.

\section{Figure 1: Age specific fertility curves for some selected African countries}

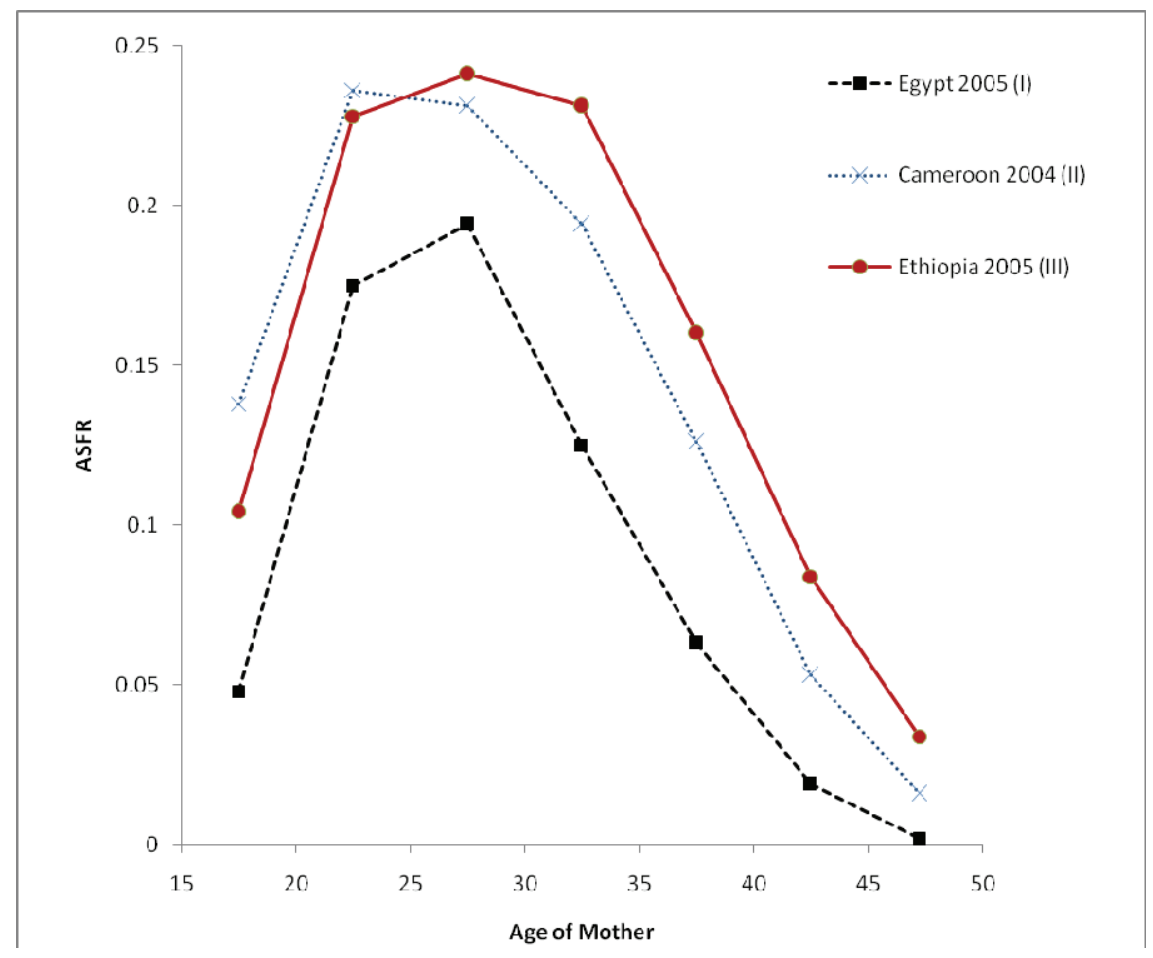


These features are summarized for each category below:

\author{
Category I (example: Egypt) \\ Low f15 \\ Peak in late $20 \mathrm{~s}$ \\ Rapid drop after late 20s \\ Very low rates in 40 s

\section{Category II (example: Cameroon)} \\ High f15 \\ Peak in early 20 s \\ Rate of dropping after the peak not rapid
}

\author{
Category III (example: Ethiopia) \\ High f15 \\ Broad peak that extends from early 20 s to early 30 s \\ Rapid drop after the early $30 \mathrm{~s}$ \\ Very high rates in 40 s
}

These features are commonly exhibited in the fertility pattern of African countries, particularly those of categories II and III, though they may not be exhibited in the fertility pattern of the developed countries. Since many developed countries have TFR below the replacement level, it is necessary to have new, more suitable parametric model(s) to study the differing fertility patterns of African countries.

Notwithstanding the various patterns noticed in the age-specific fertility curves of African countries, the continent, like other parts of the world is experiencing a fertility transition. This transition, however, is very different from those experienced in other places with similar levels of fertility (e.g., Asia and the Middle East). Unlike Africa, in some Asian countries, there are strong proscriptions against female premarital sexual activity and the great majority of brides are probably virgins (Caldwell, Orubuloye, and Caldwell 1992). The African sexual pattern is different. It is characterized by widespread premarital sexual relationship for both females and males. In fact, about four-fifths of urban women and two-thirds of rural women that were studied claimed to not have been virgins at the time of marriage (Orubuloye, Caldwell, and Caldwell 1991). Studies by Caldwell, Orubuloye, and Caldwell (1992) have also pointed out that there is similarity in contraceptive usage and fertility decline at all ages, both inside and outside marriage in Africa and that this pattern presents a new type of demographic transition to the world. In Asia and Europe, on the contrary, fertility declines are usually nonexistent or very moderate, below age 25 . The decline starts gradually and increases with age reaching a significant $30 \%$ after the age of 40 . Therefore, age-specific fertility 
curves in Africa, are more likely to be different from those found outside Africa and hence, fertility models developed and adequately used for the latter are likely to be insufficient for the former.

\section{Models for fertility schedules}

Various types of models have been proposed for modeling the one-year age specific fertility curves of many populations, but fitting these models to curves of African populations, with the attendant high-fertility levels, has not been sufficiently undertaken. Among them are the Coale-Trussell function (Coale and Trussell 1974, 1978); the Pearson Type 1 (Mitra 1967; Romaniuk 1973); Type III curves (Nurul Islam and Mallick 1987); the Beta and Gamma functions (Hoem et al. 1981); the Hadwiger function (Hadwiger 1940; Gilje 1969); and the cubic splines model (Hoem and Rennermalm 1978; Gilks, 1986).

Others are the Brass procedures (Brass 1974, 1979); the Gompertz curve (Wunsch 1966; Murphy and Nagnur 1972; Fraid 1973); the polynomial models (Brass 1960); and the quadratic spline function by Schmertmann (2003). Islam and Ali (2004) proposed a bi-quadratic polynomial model for the ASFR of a rural area of Bangladesh. Considering the recent increase noticed in the fertility rate of young women in developed countries such as the UK, Ireland and the US, Peristera and Kostaki (2007) proposed two models (which they refer to as Model 1 and Model 2, respectively) to model the pattern. All these models have been found to provide excellent fit for the one-year age-specific fertility distributions of populations with natural fertility, transitional fertility, and controlled fertility. A detailed descriptions of the mathematical formulae of most of the models can be found in Hoem et al. (1981) and Peristera and Kostaki (2007).

It might be possible to fit these models to African fertility data but the results obtained may not be very accurate. A quick look at the individual models reveals the reason for this lack of accuracy. The Coale-Trussell function can be considered unsuitable because of its orientation to fertility control. It focuses on marital fertility; the parameters determining the shape of the curve are age of marriage, proportion marrying, and the degree of fertility control (Chandola, Coleman, and Hiorns 1999). The contribution of non-marital fertility to the current fertility patterns in Africa cannot be overlooked in any fertility study in the region. The computation required by the function can also be daunting. Nonetheless, the Coale-Trussell function yielded good results when applied to a fertility schedule by Hoem et al. (1981), and Schmertmann (2003). To determine the age distribution of fertility using the Pearson Type 1 curve, values for the average age, variance, asymmetry, and kurtosis are needed which are not often provided with the other fertility data of African countries. Some simplifications of 
the curve, however, enable estimates to be made from the mean and modal ages of fertility. Most work on this distribution has been devoted to the projection of fertility and future birth, as is the case with Gompertz models, which also focuses on marital fertility through its parameters (Romaniuk 1973).

Polynomial and spline models when elevated to a suitable degree can be made to fit fertility curves well, but the lack of meaningful parameters makes them ill-suited for comparative purposes, and as a result, their use has been limited. Unmodified gamma and beta distributions may not generate curves of appropriate shape for African fertility. However, the modified versions of these distributions by Hoem et al. (1981) were found to be useful for fitting Danish fertility curves. Also, studies have revealed that the Hadwiger function is more suited for smooth fertility curves (see Chandola, Coleman, and Hiorns 1999), and that it has a common problem of overestimating fertility data towards the end of the reproductive age (Hoem et al. 1981). Hence, it may not be appropriate for fitting African fertility curves. The Quadratic spline model by Schmertmann (2003) might be more appropriate, but using the model requires the use of an author provided program (Schmertmann 2005); which is accessible via the internet. Without this program estimating the parameters can be awkward, unfortunately, using the internet for this purpose can be challenging for some researchers in the African region who may lack sufficient internet access. These researchers would prefer using more accessible, alternative models when available.

To accurately model fertility patterns in Africa, a new mathematical model that is both easily used, and provides good fit for the data is required. Such a model could reveal important parameters which need to be taken into account when comparing fertility between countries and across time. This undoubtedly would increase our understanding of fertility pattern in the region.

\section{The model}

The model we present in this work is a two-component model with the second component being a constant term. Chandola, Coleman, and Hiorns (1999) first considered the possibility of incorporating a separate term into the Hadwiger functions to handle excess early-age fertility. Similar work was done by Peristera and Kostaki (2007) in Model 2 when modeling the excess early age fertility of the UK, Ireland and the US.

We present the following model for the ASFR pattern. The model uses the error function and will therefore be referred to as the Adjusted Error Model (AEM). It is given by 


$$
f\left(x \mid a, b, \mu, s_{1}, s_{2}\right)=a+b \cdot \begin{cases}\operatorname{Erfc}\left[\left(\frac{x-\mu}{s_{1}}\right)^{2}\right] & \text { if } x \leq \mu \\ \operatorname{Erfc}\left[\left(\frac{x-\mu}{s_{2}}\right)^{2}\right] & \text { if } x>\mu\end{cases}
$$

where $\operatorname{Erfc}()$ is the complementary error function and is defined as

$$
\operatorname{Erfc}(z)=\frac{2}{\sqrt{\pi}} \int_{z}^{\infty} e^{-t^{2}} d t
$$

$f(x)$ is the ASFR at age $x$ of the mother, $b$ is the modal fertility rate $\mu$ is the mean age of motherhood while $s_{1}$ and $s_{2}$ are the spread of the distribution of the age at their respective points of reference. The constant $a$ approximates the fertility rate in the age group 45-49.

The parameters of the proposed model were estimated by minimizing the following sum of square residual (SSQ):

$$
\sum_{x}\left(f_{x}-\hat{f}_{x}\right)^{2}
$$

where $f_{x}$ is the empirical fertility rate at age $x$ and $\hat{f}_{x}$ is the estimate of $f_{x}$.

It is common when modeling fertility, and it is required to determine the performances of a number of models, to plot the predicted values of the models alongside the observed curve and then to pick the model that has the best fit; if any model stands out as obviously better than the others. Alternatively, SSQ for all the models will be computed and the model with least SSQ will be preferred. These methods cannot be said to have balanced both model fit and model complexity caused by the addition of more parameters. In this paper, we have chosen to use the Akaike's Information Criterion (AIC) (Akaike 1974) displayed in (4.3) as a measure of selecting model with best fit among the models that have been fitted to the fertility data of African countries alongside the proposed AEM. The AIC is a criterion for comparing alternative functions by adjusting the SSQ for the number of observations and the number of parameters in the model. The criterion can be used to decide if the improved fit is worth the decreased degrees of freedom and the increased complexity of the function caused by the addition of another parameter to a model.

The variant of the AIC used in this paper is given by

$$
A I C=2 k+n \ln \left[\frac{S S Q}{n-k}\right]
$$

where $k$ is the number of parameters in the model and $n$ is the number of observations. When comparing the performances of a number of models, the model with least AIC is usually preferred as the best. The AIC procedure has been discussed and successfully 
used to identify model with best fit by Akaike (1977), Tong (1977), Ozaki (1977), Larimore and Mehra (1985), and Koehler and Murphree (1988), among others.

\section{Evaluation of the model}

In order to determine the performance of the proposed model, we fit it alongside five other commonly used models namely; the Quadratic spline (QS), Beta function, Gamma function, Hadwiger function, Model 2, and to the empirical five-year fertility data of 15 African countries. Age-specific fertility datasets for these countries are based on a five-year fertility instead of single-year age. Hence, all analyses are based on a five-year age. The data for all countries were obtained directly from published reports of Demographic and Health Survey (DHS) (available online from ORC Macro's website http://www.measuredhs.com). For the purposes of this study, the following countries were included in the analyses: Burkina Faso (2003), Cameroon (2004), Chad (2004), Ethiopia (2005), Egypt (2005), Ghana (2003), Kenya (2003), Morocco (200304), Namibia (2000), and Niger (2006). Additionally, Nigeria (2003), Rwanda (2005), Senegal (2005), South Africa (2003), and Zambia (2000-01) were included. The latest available reports for these countries at the time of this research were used. The parameter estimates for the models were obtained by minimizing the SSQ. This was accomplished with the aid of the inbuilt solver in MS Excel. Luckily, the complementary error function used in proposing the AEM is one of the inbuilt functions in MS Excel. The Quadratic spline estimates were obtained using the program provided by Schmertmann (2005) (available at the web page http://www.demographicresearch.org/Volumes/Vol12/5/qsfit/qsfit.html).

Tables 1 to 15 in Appendix A present the results of the estimates. The Tables provide the empirical fertility data for each of the countries, the fitted values from each of the six models, the values of the SSQ, the number of parameters, and the values of the AIC. The least AIC value for each case is written in bold case. We also present the parameter estimates of the AEM for selected countries in Table 16. These show the nature of the estimates for each of the model's parameters. Moreover, in Appendix B, the plots of the empirical and fitted values of the models for three countries are presented in Figures 2 to 4 . Figure 5 presents the relationship between parameter $b$ of the AEM and the modal fertility rate while the relationship between parameter $a$ and the fertility rate at the age group 45-49 is presented in Figures 6.

Results from Tables 1 to 15 reveal that the values of the AIC for the AEM is lowest for 11 of the 15 countries considered. This shows that this model is better able to reproduce the empirical fertility data of African countries than the other existing models considered. The QS has the least AIC values for 3 of the countries, namely, Egypt, 
South Africa and Zambia while the Hadwiger model has the lowest for Namibia. The SSQ value of the AEM is lower than that of the QS for Zambia but QS is preferred in reproducing the empirical data by the selection criterion because it has fewer parameters. The same is the case for Namibia where the SSQ of AEM, Beta, Gamma and Model 2 are lower than that of the Hadwiger but the Hadwiger model has the lower AIC because it has fewer parameters.

The strong association between the estimates of the AEM parameters and some features of African fertility allows them to be given demographic interpretations. Some possible interpretations can be explored in Figures 5 and 6 . The correlation between the constant parameter $a$ and the fertility rate in the age group $45-49$ is found to be significant. Parameter $b$ is strongly associated with the modal fertility rate as evident from Figure 5. The $\mu$ parameter is found to relate well with the mean age of motherhood (estimates for selected countries are provided in Table 16) while estimates of $s_{1}$ and $s_{2}$ can best describe the spread of the fertility distribution.

It is worth noting that the AEM is a flexible model that captures the fertility pattern of countries from different parts of Africa well. The model can reproduce the patterns of fertility for those countries whose fertility data demonstrate apparent support for a demographic transition from high to much lower fertility levels; those that have recorded a small decline in TFR, as well as those whose fertility level seems to have stabilized as described by Makinde-Adebusoye (2001). Egypt and Zambia were categorized as countries experiencing a decline from high to much lower fertility. The fertility patterns of these countries are similar to that of South Africa as they were altogether better captured by the QS; one may therefore infer that South Africa also belongs to this category. Another remarkable observation from the results obtained indicates that the Beta model does better than the Gamma for most of the data considered in this study using the AIC as a tool for model choice. This supports the results of Peristera and Kostaki (2007) when both models, among others, were applied to the fertility pattern of "modern population." Moreover, plots of the empirical and fitted values of the ASFR as displayed in Figures 2, 3, and 4 all reveal that the Hadwiger function overestimated the curves at the peak and towards the end; a problem which has long been noticed with the function by Hoem et al. (1981).

\section{Conclusions}

Despite the wide range of models proposed for demographic variables in the literature, not much has been specifically put forward to model the ASFR of African countries. In this work, an Adjusted Error model, which is flexible enough to capture the varying fertility patterns of African countries and that has parameters that can be interpreted in 
terms of demographic indices is presented. The performance of this model alongside some other commonly used models was evaluated using the fertility data of 15 African countries. Using AIC as a model selection criterion, it was determined that the model we propose has the best fit for 11 out of 15 countries. The Quadratic spline has the best fit for 3 , while the Hadwiger model captures that of only 1 country better.

\section{Acknowledgements}

The authors would like to acknowledge the constructive comments from two anonymous reviewers and the Associate Editor. These have helped in improving this paper to a publishable standard. 


\section{References}

Akaike, H. (1974). A new look at the statistical model identification. IEEE Transactions on Automatic Control 19(6): 716-723. doi:10.1109/ TAC.1974.1100705.

Akaike, H. (1977). Canonical correlation analysis of time series and the use of the information criterion. In: Mehra, R.K. and Laintiotis, D.G. (eds.). System Identification: Advances and Case studies. New York: Academic Press: 27-96.

Brass, W. (1960). The graduation of fertility distributions by polynomial functions. Population Studies 14(2): 148-162. doi:10.2307/2172011.

Brass, W. (1974). Perspective in population prediction: Illustrated by the Statistics of England and Wales. Journal of the Royal Statistical Society, Series A (General) 137(4): 532-583. doi:10.2307/2344713.

Brass, W. (1979). Population projections for planning and policy. Honolulu, Hawaii: East West Population Institute (Papers of the East West Population Institute, No 55).

Caldwell, J.C. (1980). Mass education as a determinant of the timing of fertility decline. Population and Development Review 6(2): 225-255. doi:10.2307/1972729.

Caldwell, J.C., Orubuloye, I.O., and Caldwell, P. (1992). Fertility decline in Africa: A new type of transition? Population and Development Review 18(2): 211-242. doi: $10.2307 / 1973678$.

Chandola, T., Coleman, D.A., and Hiorns, R.W. (1999). Recent European fertility patterns: Fitting curves to 'distorted' distributions. Population Studies 53(3): 317-329. doi:10.1080/00324720308089.

Coale, A.J. and Trussell, T.J. (1974). Model fertility schedules: Variations in the age structure of childbearing in human populations. Population Index 40(2): 185-258. doi: $10.2307 / 2733910$.

Coale, A.J. and Trussell, T.J. (1978). Technical note: Finding the two parameters that specify a model schedule of marital fertility. Population Index 44(2): 203-213. doi: $10.2307 / 2735537$.

Demographic and Health Survey (2008). ORC Macro website [electronic resource] http://www.measuredhs.com.

Fraid, S.M. (1973). On the pattern of cohort fertility. Population Studies 27(1): 159-168. doi:10.2307/2173460. 
Gilje, E. (1969). Fitting curves to age-specific fertility rates: Some examples. Statistical Review of the Swedish National Central Bureau of Statistics III 7: 118-134.

Gilks, W.R. (1986). The relationship between birth history and current fertility in developing countries. Population Studies 40(3): 437-455. doi:10.1080/0032472031000142346.

Hadwiger, H. (1940). Eine analytische Reprodutionsfunktion für biologische Gesamtheiten. Skandinavisk Aktuarietidskrift 23: 101-113.

Hoem, J.M., Madsen, D., Nielsen, J.L., Ohlsen, E.-M., Hansen, H.O., and Rennermalm, B. (1981). Experiments in modeling recent Danish fertility curves. Demography 18(2): 231-244. doi:10.2307/2061095.

Hoem, J.M. and Rennermalm, B. (1978). On the statistical theory of graduation by splines. Copenhagen: University of Copenhagen, Laboratory of Actuarial Mathematics (Working Paper No. 14).

Islam, M.R. and Ali, M.K. (2004). Mathematical modeling of age specific fertility rates and study the reproductivity in the rural area of Bangladesh during 1980-1998. Pakistan Journal of Statistics 20(3): 379-392.

Koehler, A.B. and Murphree, E.S. (1988). A comparison of results from state space forecasting with forecasts from the Makridakis competition. International Journal of Forecasing 4(1): 45-55. doi:10.1016/0169-2070(88)90009-X.

Larimore, W.E. and Mehra, R.K. (1985). Problem of overfitting data. Byte 10(10): 167-178.

Makinde-Adebusoye, P. (2001). Social-cultural factors affecting fertility in Sub Saharan Africa. Paper presented at the Workshop on prospects for fertility decline in high fertility countries, Population Division, Department of Economic and Social Affairs, UN Secretariat, New York, July 9-11, 2001.

Mitra, S. (1967): The pattern of age-specific fertility rates. Demography 4(2): 894-906. doi:10.2307/2060327.

Murphy, E.M. and Nagnur, D.N. (1972). A Gompertz fit that fits: Applications to Canadian fertility patterns. Demography 9(1): 35-50. doi:10.2307/2060544.

Norville, C., Gomez, R., and Brown, R.L. (2003). Some causes of fertility rates movements. University of Waterloo, Institute of Insurance and Pension Research. (Research report 03-02). http://www.stats.uwaterloo.ca/stats navigation/IIPR/2003Reports/03-02.pdf. 
Nurul Islam, M. and Mallick, S.A. (1987). On the use of a truncated Pearsonian Type III curve in fertility estimation. Dhaka University Studies Part B Science 35(1): 23-32.

Orubuloye, I.O., Caldwell, J.C., and Caldwell, P. (1991). Sexual networking in the Ekiti District of Nigeria. Studies in Family Planning 22(2): 61-73. doi:10.2307/1966777.

Ozaki, T. (1977). On the order determination of ARIMA models. Journal of the Royal Statistical Society. Series C (Applied Statistics) 26(3): 290-301. doi:10.2307/2346970.

Peristera, P. and Kostaki, A. (2007). Modeling fertility in modern populations. Demographic Research 16(6): 141-194. doi:10.4054/DemRes.2007.16.6.

Romaniuk, A. (1973). A three parameter mode for birth projections. Population Studies 27(3): 467-478. doi:10.2307/2173766.

Salomon, J.A. and Murray, C.J.L. (2001). Modelling HIV/AIDS epidemic in subSaharan Africa using seroprevalence data from antenatal clinics. Bulletin of the World Health Organization 79(7): 596-606. http://www.scielosp.org/ scielo.php?script=sci_arttext\&pid=S0042-96862001000700004\&lng=en\&nrm =iso. doi:10.1590/S0042-96862001000700004.

Schmertmann, C. (2003). A system of model fertility schedules with graphical intuitive parameters. Demographic Research 9(5): 81-110. doi:10.4054/DemRes.2003.9.5.

Schmertmann, C. (2005). Quadratic spline fits by nonlinear least squares. Demographic Research 12(5): 105-106. doi:10.4054/DemRes.2005.12.5.

Tong, H. (1977). Some comments on the Canadian lynx data. Journal of the Royal Statistical Society Series A (General) 140(4): 432-436. doi:10.2307/2345278.

United Nations (2000). [electronic resource] http://www.un.org/millenniumgoals/.

Wunsch, G. (1966). Courbes de Gompertz et perspectives de fecondité. Recherches Economiques de Louvain 32(6): 457-468. 


\section{Appendix A}

Table 1: Empirical and fitted values for the ASFR for Burkina Faso with values of minimization and model selection criterion

\begin{tabular}{lccccccc}
\hline \multicolumn{7}{c}{ Data } & \multicolumn{7}{c}{ Burkina Faso 2003 } \\
Model Fit \\
\hline Age & DHS & AEM & QS & Beta & Gamma & Hadwiger & Model 2 \\
$15-20$ & $\mathbf{1 3 8}$ & 131 & 131 & 137 & 152 & 136 & 135 \\
$20-25$ & $\mathbf{2 7 5}$ & 274 & 275 & 263 & 243 & 261 & 261 \\
$25-30$ & $\mathbf{2 7 1}$ & 274 & 269 & 281 & 284 & 289 & 285 \\
$30-35$ & $\mathbf{2 4 1}$ & 238 & 240 & 242 & 252 & 239 & 243 \\
$35-40$ & $\mathbf{1 8 1}$ & 180 & 187 & 176 & 175 & 166 & 174 \\
$\mathbf{4 0 - 4 5}$ & $\mathbf{1 0 6}$ & 108 & 107 & 105 & 97 & 103 & 103 \\
$\mathbf{4 5 - 4 9}$ & $\mathbf{4 2}$ & 41 & 19 & 45 & 44 & 59 & 46 \\
& & & & & & & \\
$\mathbf{1 0}$. SSQ & & 21.8 & 549 & 320 & 1897 & 1124 & 474 \\
K & & 5 & 4 & 5 & 4 & 3 & 6 \\
AIC & & $-\mathbf{7 0 . 0}$ & -52.2 & -51.2 & -43.6 & -51.2 & -41.6 \\
\hline
\end{tabular}

Data source: http://www.measuredhs.com/pubs/pdf/FR154/04Chapitre4.pdf , Table 4.1 p. 48.

Table 2: $\quad$ Empirical and fitted values for the ASFR for Cameroon with values of minimization and model selection criterion

\begin{tabular}{|c|c|c|c|c|c|c|c|}
\hline \multicolumn{8}{|c|}{ Cameroon 2004} \\
\hline \multicolumn{2}{|c|}{ Data } & \multicolumn{5}{|c|}{ Model Fit } & \multirow[b]{2}{*}{ Model 2} \\
\hline Age & DHS & AEM & QS & Beta & Gamma & Hadwiger & \\
\hline $15-20$ & 138 & 138 & 138 & 140 & 144 & 133 & 139 \\
\hline $20-25$ & 236 & 235 & 235 & 229 & 223 & 238 & 233 \\
\hline $25-30$ & 231 & 234 & 236 & 241 & 243 & 242 & 238 \\
\hline $30-35$ & 194 & 192 & 188 & 191 & 194 & 181 & 190 \\
\hline $35-40$ & 126 & 124 & 126 & 119 & 118 & 114 & 123 \\
\hline $40-45$ & 53 & 56 & 60 & 58 & 56 & 64 & 60 \\
\hline $45-49$ & 16 & 15 & 9 & 20 & 21 & 33 & 13 \\
\hline \multicolumn{2}{|c|}{$10^{6} . \mathrm{SSQ}$} & 24.0 & 158 & 234 & 451 & 856 & 137 \\
\hline \multicolumn{2}{|l|}{ K } & 5 & 4 & 5 & 4 & 3 & 6 \\
\hline \multicolumn{2}{|l|}{ AIC } & -69.3 & -61.0 & -53.4 & -53.6 & -53.1 & -50.3 \\
\hline
\end{tabular}

Data source: http://www.measuredhs.com/pubs/pdf/FR163/04chapitre04.pdf , Table 4.1 p. 62. 
Table 3: Empirical and fitted values for the ASFR for Chad with values of minimization and model selection criterion

\begin{tabular}{lrrrrrrr}
\hline \multicolumn{2}{c}{ Data } & \multicolumn{7}{c}{ Chad 2004 } \\
\hline Age & DHS & AEM & QS & Beta & Gamma & Hadwiger & Model 2 \\
$15-20$ & $\mathbf{1 8 7}$ & 188 & 180 & 189 & 189 & 177 & 189 \\
$20-25$ & $\mathbf{2 9 5}$ & 289 & 310 & 285 & 280 & 299 & 286 \\
$25-30$ & $\mathbf{2 7 5}$ & 292 & 291 & 295 & 302 & 301 & 295 \\
$30-35$ & $\mathbf{2 6 3}$ & 246 & 255 & 246 & 245 & 229 & 245 \\
$35-40$ & $\mathbf{1 6 3}$ & 166 & 194 & 165 & 155 & 148 & 165 \\
$\mathbf{4 0 - 4 5}$ & $\mathbf{7 3}$ & 76 & 107 & 78 & 78 & 86 & 81 \\
$\mathbf{4 5 - 4 9}$ & $\mathbf{1 3}$ & 12 & 18 & 15 & 32 & 47 & 9 \\
& & & & & & & \\
$\mathbf{1 0}{ }^{6}$. SSQ & & 636 & 2700 & 814 & 1713 & 3498 & 897 \\
K & & 5 & 4 & 5 & 4 & 3 & 6 \\
AIC & & -46.4 & -41.1 & -44.6 & -44.3 & -43.3 & -37.1 \\
\hline
\end{tabular}

Data source: http://www.measuredhs.com/pubs/pdf/FR170/04Chapitre04.pdf , Table 4.1 p. 57.

Table 4: Empirical and fitted values for the ASFR for Ethiopia with values of minimization and model selection criterion

\begin{tabular}{lrrrrrrr}
\hline \multicolumn{1}{c}{ Data } & \multicolumn{7}{c}{ Ethiopia 2005 } \\
\hline Age & DHS & AEM & QS & Beta & Gamma & Hadwiger & Model 2 \\
$15-20$ & $\mathbf{1 0 4}$ & 105 & 104 & 105 & 117 & 102 & 105 \\
$20-25$ & $\mathbf{2 2 8}$ & 224 & 226 & 223 & 207 & 222 & 224 \\
$25-30$ & $\mathbf{2 4 1}$ & 251 & 248 & 251 & 255 & 260 & 251 \\
$30-35$ & $\mathbf{2 3 1}$ & 221 & 219 & 222 & 230 & 217 & 220 \\
$35-40$ & $\mathbf{1 6 0}$ & 160 & 164 & 160 & 157 & 149 & 160 \\
$\mathbf{4 0 - 4 5}$ & $\mathbf{8 4}$ & 87 & 91 & 89 & 83 & 90 & 92 \\
$\mathbf{4 5 - 4 9}$ & $\mathbf{3 4}$ & 33 & 16 & 31 & 35 & 50 & 31 \\
& & & & & & & \\
$\mathbf{1 0}$. SSQ & & 226 & 595 & 256 & 847 & 991 & 315 \\
K & & 5 & 4 & 5 & 4 & 3 & 6 \\
AIC & & -53.6 & -51.7 & -52.7 & -49.2 & -52.1 & -44.4 \\
\hline
\end{tabular}

Data source: http://www.measuredhs.com/pubs/pdf/FR179/FR179.pdf , Table 4.1 p. 47. 
Table 5: Empirical and fitted values for the ASFR for Egypt with values of minimization and model selection criterion

\begin{tabular}{|c|c|c|c|c|c|c|c|}
\hline \multicolumn{8}{|c|}{ Egypt 2005} \\
\hline \multicolumn{2}{|c|}{ Data } & \multicolumn{6}{|c|}{ Model Fit } \\
\hline Age & DHS & AEM & QS & Beta & Gamma & Hadwiger & Model 2 \\
\hline $15-20$ & 48 & 47 & 48 & 50 & 49 & 53 & 67 \\
\hline $20-25$ & 175 & 177 & 175 & 175 & 174 & 170 & 157 \\
\hline $25-30$ & 194 & 187 & 194 & 193 & 195 & 197 & 199 \\
\hline $30-35$ & 125 & 134 & 125 & 128 & 125 & 127 & 135 \\
\hline $35-40$ & 63 & 59 & 62 & 59 & 58 & 57 & 49 \\
\hline $40-45$ & 19 & 15 & 22 & 19 & 22 & 20 & 10 \\
\hline $45-49$ & 2 & 6 & 3 & 4 & 7 & 6 & 1 \\
\hline $10^{6} . S S Q$ & & 178 & 12.7 & 29.6 & 62.1 & 118 & 1070 \\
\hline $\mathbf{K}$ & & 5 & 4 & 5 & 4 & 3 & 6 \\
\hline AIC & & -55.3 & -78.6 & -67.8 & -67.5 & -67.0 & -35.9 \\
\hline
\end{tabular}

Data source: http://www.measuredhs.com/pubs/pdf/FR176/04Chapter04.pdf , Table 4.1 p. 44.

Table 6: Empirical and fitted values for the ASFR for Ghana with values of minimization and model selection criterion

\begin{tabular}{lrrrrccc}
\hline \multicolumn{1}{c}{ Data } & \multicolumn{7}{c}{ Ghana 2003 } \\
\hline Age & DHS & AEM & QS & Beta & Gamma & Hadwiger & Model 2 \\
$15-20$ & $\mathbf{7 4}$ & 74 & 74 & 74 & 76 & 73 & 73 \\
$20-25$ & $\mathbf{1 7 6}$ & 176 & 176 & 175 & 172 & 174 & 178 \\
$25-30$ & $\mathbf{2 1 0}$ & 209 & 207 & 210 & 213 & 215 & 208 \\
$30-35$ & $\mathbf{1 8 2}$ & 186 & 185 & 186 & 187 & 184 & 185 \\
$35-40$ & $\mathbf{1 4 1}$ & 135 & 139 & 132 & 129 & 127 & 134 \\
$40-45$ & $\mathbf{7 0}$ & 74 & 77 & 77 & 76 & 77 & 78 \\
$\mathbf{4 5 - 4 9}$ & $\mathbf{3 6}$ & 35 & 14 & 35 & 39 & 42 & 32 \\
& & & & & & & \\
$\mathbf{1 0} \mathbf{C}^{- \text {SSQ }}$ & & 74.3 & 568 & 136 & 244 & 302 & 148 \\
$\mathbf{K}$ & & 5 & 4 & 5 & 4 & 3 & 6 \\
AIC & & -61.4 & -52.0 & -57.2 & -57.9 & -60.5 & -49.7 \\
\hline
\end{tabular}

Data source: http://www.measuredhs.com/pubs/pdf/FR152/04Chapter4.pdf , Table 4.1 p. 54. 
Table 7: Empirical and fitted values for the ASFR for Kenya with values of minimization and model selection criterion

\begin{tabular}{lrrrrccc}
\hline \multicolumn{2}{c}{ Data } & \multicolumn{7}{c}{ Kenya 2003 } \\
\hline Age & DHS & AEM & QS & Beta & Gamma & Hadwiger & Model 2 \\
$15-20$ & $\mathbf{1 1 4}$ & 114 & 114 & 118 & 118 & 117 & 116 \\
$20-25$ & $\mathbf{2 4 3}$ & 242 & 242 & 235 & 232 & 234 & 234 \\
$25-30$ & $\mathbf{2 3 1}$ & 235 & 237 & 242 & 248 & 248 & 244 \\
$30-35$ & $\mathbf{1 9 6}$ & 191 & 187 & 191 & 187 & 186 & 191 \\
$35-40$ & $\mathbf{1 2 3}$ & 124 & 126 & 121 & 114 & 113 & 119 \\
$\mathbf{4 0 - 4 5}$ & $\mathbf{5 5}$ & 56 & 60 & 57 & 59 & 60 & 57 \\
$45-49$ & $\mathbf{1 5}$ & 14 & 9 & 16 & 28 & 29 & 16 \\
& & & & & & & \\
$\mathbf{1 0} \mathbf{6}^{6} . \mathbf{S S Q}$ & & 46.9 & 179 & 226 & 757 & 829 & 283 \\
$\mathbf{K}$ & & 5 & 4 & 5 & 4 & 3 & 6 \\
AIC & & -64.6 & -60.1 & -53.6 & -50.0 & -53.4 & -45.1 \\
\hline
\end{tabular}

Data source: http://www.measuredhs.com/pubs/pdf/FR151/04Chapter04.pdf , Table 4.1 p. 52.

Table 8: Empirical and fitted values for the ASFR for Morocco with values of minimization and model selection criterion

\begin{tabular}{|c|c|c|c|c|c|c|c|}
\hline \multicolumn{8}{|c|}{ Morocco 2003-2004 } \\
\hline \multicolumn{2}{|c|}{ Data } & \multicolumn{5}{|c|}{ Model Fit } & \multirow[b]{2}{*}{ Model 2} \\
\hline Age & DHS & AEM & QS & Beta & Gamma & Hadwiger & \\
\hline $15-20$ & 32 & 35 & 34 & 33 & 37 & 30 & 31 \\
\hline $20-25$ & 104 & 99 & 99 & 100 & 95 & 99 & 105 \\
\hline $25-30$ & 124 & 132 & 134 & 132 & 135 & 137 & 129 \\
\hline $30-35$ & 125 & 120 & 115 & 119 & 120 & 115 & 115 \\
\hline $35-40$ & 78 & 79 & 76 & 78 & 73 & 71 & 79 \\
\hline $40-45$ & 28 & 29 & 36 & 31 & 33 & 36 & 36 \\
\hline $45-49$ & 5 & 4 & 6 & 4 & 11 & 16 & 0 \\
\hline $10^{6} . \mathrm{SSQ}$ & & 123 & 293 & 123 & 340 & 540 & 223 \\
\hline $\mathbf{K}$ & & 5 & 4 & 5 & 4 & 3 & 6 \\
\hline AIC & & -57.9 & -56.6 & -57.9 & -55.6 & -56.4 & -46.8 \\
\hline
\end{tabular}

Data source: http://www.measuredhs.com/pubs/pdf/FR155/04Chapitre04.pdf , Table 4.1 p. 44. 
Table 9: Empirical and fitted values for the ASFR for Namibia with values of minimization and model selection criterion

\begin{tabular}{|c|c|c|c|c|c|c|c|}
\hline \multicolumn{8}{|c|}{ Namibia 2000} \\
\hline \multicolumn{2}{|c|}{ Data } & \multicolumn{5}{|c|}{ Model Fit } & \multirow[b]{2}{*}{ Model 2} \\
\hline Age & DHS & AEM & QS & Beta & Gamma & Hadwiger & \\
\hline $15-20$ & 88 & 89 & 78 & 89 & 94 & 86 & 90 \\
\hline $20-25$ & 166 & 164 & 165 & 163 & 154 & 163 & 159 \\
\hline $25-30$ & 176 & 180 & 162 & 179 & 183 & 186 & 181 \\
\hline $30-35$ & 160 & 162 & 155 & 163 & 167 & 160 & 165 \\
\hline $35-40$ & 137 & 126 & 134 & 126 & 123 & 118 & 126 \\
\hline $40-45$ & 71 & 79 & 93 & 80 & 76 & 78 & 79 \\
\hline $45-49$ & 38 & 36 & 34 & 35 & 40 & 49 & 36 \\
\hline \multicolumn{2}{|c|}{$10^{6} . \mathrm{SSQ}$} & 206 & 830 & 236 & 493 & 637 & 292 \\
\hline \multicolumn{2}{|l|}{ K } & 5 & 4 & 5 & 4 & 3 & 6 \\
\hline \multicolumn{2}{|l|}{ AIC } & -54.3 & -49.3 & -53.3 & -53.0 & -55.2 & -45.0 \\
\hline
\end{tabular}

Data source: http://www.measuredhs.com/pubs/pdf/FR141/03chapter03-a.pdf, Table 4.1 p. 47.

Table 10: Empirical and fitted values for the ASFR for Niger with values of minimization and model selection criterion

\begin{tabular}{lrrrrccc}
\hline \multicolumn{2}{c}{ Data } & \multicolumn{7}{c}{ Niger 2006 } \\
\hline Age & DHS & AEM & QS & Beta & Gamma & Hadwiger & Model 2 \\
$15-20$ & $\mathbf{1 9 9}$ & 199 & 199 & 200 & 200 & 190 & 201 \\
$20-25$ & $\mathbf{3 0 2}$ & 298 & 301 & 297 & 291 & 306 & 292 \\
$25-30$ & $\mathbf{2 9 6}$ & 305 & 300 & 307 & 314 & 315 & 309 \\
$30-35$ & $\mathbf{2 7 1}$ & 267 & 265 & 266 & 267 & 254 & 268 \\
$35-40$ & $\mathbf{2 0 3}$ & 197 & 203 & 195 & 186 & 179 & 194 \\
$\mathbf{4 0 - 4 5}$ & $\mathbf{1 0 5}$ & 112 & 115 & 114 & 110 & 115 & 112 \\
$\mathbf{4 5 - 4 9}$ & $\mathbf{4 4}$ & 42 & 20 & 41 & 57 & 70 & 42 \\
& & & & & & & \\
$\mathbf{1 0}$. SSQ & & 208 & 698 & 325 & 935 & 2099 & 419 \\
K & & 5 & 4 & 5 & 4 & 3 & 6 \\
AIC & & -54.2 & -50.6 & -51.1 & -48.5 & -46.9 & -45.0 \\
\hline
\end{tabular}

Data source: http://www.measuredhs.com/pubs/pdf/FR193/04Chapitre04.pdf , Table 4.1 p. 56. 
Table 11: Empirical and fitted values for the ASFR for Nigeria with values of minimization and model selection criterion

\begin{tabular}{|c|c|c|c|c|c|c|c|}
\hline \multicolumn{8}{|c|}{ Nigeria 2003} \\
\hline \multicolumn{2}{|c|}{ Data } & \multicolumn{5}{|c|}{ Model Fit } & \multirow[b]{2}{*}{ Model 2} \\
\hline Age & DHS & AEM & QS & Beta & Gamma & Hadwiger & \\
\hline $15-20$ & 126 & 126 & 127 & 126 & 124 & 108 & 128 \\
\hline $20-25$ & 229 & 230 & 226 & 230 & 227 & 242 & 226 \\
\hline $25-30$ & 274 & 272 & 277 & 273 & 280 & 283 & 274 \\
\hline $30-35$ & 244 & 246 & 243 & 245 & 244 & 229 & 247 \\
\hline $35-40$ & 168 & 167 & 163 & 166 & 157 & 150 & 164 \\
\hline $40-45$ & 72 & 72 & 79 & 75 & 77 & 86 & 76 \\
\hline $45-49$ & 18 & 18 & 13 & 14 & 30 & 45 & 15 \\
\hline \multicolumn{2}{|c|}{$10^{6} . \mathrm{SSQ}$} & 8.93 & 125 & 30.3 & 318 & 2006 & 59.7 \\
\hline \multicolumn{2}{|l|}{ K } & 5 & 4 & 5 & 4 & 3 & 6 \\
\hline \multicolumn{2}{|l|}{ AIC } & -76.2 & -62.6 & -67.7 & -56.1 & -47.2 & -56.1 \\
\hline
\end{tabular}

Data source: http://www.measuredhs.com/pubs/pdf/FR148/04Chapter04.pdf , Table 4.1 p. 51.

Table 12: Empirical and fitted values for the ASFR for Rwanda with values of minimization and model selection criterion

\begin{tabular}{|c|c|c|c|c|c|c|c|}
\hline \multicolumn{8}{|c|}{ Rwanda 2005} \\
\hline \multicolumn{2}{|c|}{ Data } & \multicolumn{5}{|c|}{ Model Fit } & \multirow[b]{2}{*}{ Model 2} \\
\hline Age & DHS & AEM & QS & Beta & Gamma & Hadwiger & \\
\hline $15-20$ & 42 & 42 & 42 & 59 & 50 & 63 & 41 \\
\hline $20-25$ & 235 & 235 & 235 & 222 & 224 & 215 & 238 \\
\hline $25-30$ & 305 & 304 & 304 & 307 & 316 & 314 & 301 \\
\hline $30-35$ & 273 & 275 & 274 & 285 & 278 & 285 & 277 \\
\hline $35-40$ & 211 & 209 & 211 & 202 & 190 & 193 & 206 \\
\hline $40-45$ & 117 & 118 & 120 & 110 & 112 & 108 & 118 \\
\hline $45-49$ & 32 & 32 & 22 & 43 & 59 & 54 & 35 \\
\hline \multicolumn{2}{|c|}{$10^{6} . \mathrm{SSQ}$} & 11.4 & 111 & 877 & 1523 & 1950 & 76.5 \\
\hline \multicolumn{2}{|l|}{ K } & 5 & 4 & 5 & 4 & 3 & 6 \\
\hline \multicolumn{2}{|l|}{ AIC } & -74.5 & -63.4 & -44.1 & -45.1 & -47.4 & -54.4 \\
\hline
\end{tabular}

Data source: http://www.measuredhs.com/pubs/pdf/FR183/04Chapter04.pdf , Table 4.1 p. 38. 
Table 13: Empirical and fitted values for the ASFR for Senegal with values of minimization and model selection criterion

\begin{tabular}{lrrrrccc}
\hline \multicolumn{2}{c}{ Data } & \multicolumn{7}{c}{ Senegal 2005 } \\
Age & DHS & AEM & QS & Beta & Gamma & Hadwiger & Model 2 \\
$15-20$ & $\mathbf{1 0 1}$ & 102 & 101 & 104 & 106 & 90 & 96 \\
$20-25$ & $\mathbf{2 1 2}$ & 210 & 211 & 205 & 201 & 216 & 223 \\
$25-30$ & $\mathbf{2 5 0}$ & 252 & 255 & 256 & 257 & 262 & 252 \\
$30-35$ & $\mathbf{2 2 8}$ & 230 & 225 & 232 & 233 & 220 & 221 \\
$35-40$ & $\mathbf{1 6 9}$ & 164 & 162 & 158 & 155 & 147 & 158 \\
$\mathbf{4 0 - 4 5}$ & $\mathbf{7 4}$ & 78 & 85 & 79 & 78 & 85 & 86 \\
$\mathbf{4 5 - 4 9}$ & $\mathbf{2 2}$ & 21 & 14 & 27 & 31 & 45 & 22 \\
& & & & & & & 486 \\
$\mathbf{1 0}$. SSQ & & 69.4 & 278 & 266 & 518 & 1500 & 6 \\
K & & 5 & 4 & 5 & 4 & 3 & -41.4 \\
AIC & & -61.9 & -57.0 & -52.5 & -52.6 & -49.2 & \\
\hline
\end{tabular}

Data source: http://www.measuredhs.com/pubs/pdf/FR177/04Chapitre04.pdf, Table 4.1 p. 56.

Table 14: Empirical and fitted values for the ASFR for South Africa with values of minimization and model selection criterion

\begin{tabular}{lrrrrrrr}
\hline \multicolumn{1}{c}{ Data } & \multicolumn{7}{c}{ South Africa 2003 } \\
Model Fit \\
\hline Age & DHS & AEM & QS & Beta & Gamma & Hadwiger & Model 2 \\
$15-20$ & $\mathbf{5 5}$ & 55 & 55 & 55 & 59 & 54 & 56 \\
$20-25$ & $\mathbf{1 0 2}$ & 100 & 101 & 100 & 94 & 101 & 99 \\
$25-30$ & $\mathbf{9 7}$ & 101 & 101 & 102 & 104 & 104 & 102 \\
$30-35$ & $\mathbf{8 4}$ & 82 & 80 & 82 & 83 & 78 & 82 \\
$35-40$ & $\mathbf{5 6}$ & 53 & 53 & 52 & 50 & 48 & 52 \\
$40-45$ & $\mathbf{1 8}$ & 22 & 25 & 24 & 23 & 26 & 24 \\
$\mathbf{4 5 - 4 9}$ & $\mathbf{6}$ & 4 & 4 & 4 & 8 & 13 & 4 \\
& & & & & & & \\
$\mathbf{1 0} \mathbf{C}^{\mathbf{S}} \mathbf{S S Q}$ & & 51.3 & 98.4 & 77.8 & 197 & 276 & 103 \\
$\mathbf{K}$ & & 5 & 4 & 5 & 4 & 3 & 6 \\
AIC & & -64.0 & -64.3 & -61.1 & -59.4 & -61.1 & -52.3 \\
\hline
\end{tabular}

Data source: http://www.measuredhs.com/pubs/pdf/FR206/FR206.pdf, Table 3.1 p. 44. 
Table 15: Empirical and fitted values for the ASFR for Zambia with values of minimization and model selection criterion

\begin{tabular}{lrrrrrrr}
\hline \multicolumn{2}{c}{ Data } & \multicolumn{7}{c}{ Zambia 2001-2002 } \\
Model Fit \\
\hline Age & DHS & AEM & QS & Beta & Gamma & Hadwiger & Model 2 \\
$15-20$ & $\mathbf{1 6 0}$ & 160 & 159 & 163 & 170 & 158 & 164 \\
$20-25$ & $\mathbf{2 6 6}$ & 261 & 267 & 257 & 244 & 261 & 253 \\
$25-30$ & $\mathbf{2 4 9}$ & 257 & 250 & 259 & 265 & 267 & 262 \\
$30-35$ & $\mathbf{2 1 8}$ & 219 & 218 & 220 & 225 & 212 & 221 \\
$35-40$ & $\mathbf{1 7 2}$ & 160 & 165 & 159 & 152 & 144 & 157 \\
$\mathbf{4 0 - 4 5}$ & $\mathbf{7 9}$ & 89 & 91 & 89 & 84 & 89 & 89 \\
$\mathbf{4 5 - 4 9}$ & $\mathbf{3 0}$ & 27 & 15 & 27 & 39 & 52 & 29 \\
& & & & & & & \\
$\mathbf{1 0} \mathbf{6}^{6} . \mathbf{S S Q}$ & & 346 & 398 & 490 & 1386 & 1779 & 673 \\
K & & 5 & 4 & 5 & 4 & 3 & 6 \\
AIC & & -50.6 & $\mathbf{- 5 4 . 5}$ & -48.2 & -45.8 & -48.0 & -39.1 \\
\hline
\end{tabular}

Data source: http://www.measuredhs.com/pubs/pdf/FR136/04Chapter04.pdf , Table 4.1 p. 56

Table 16: Parameter estimates of the AEM for selected countries

\begin{tabular}{lccrrr}
\hline & \multicolumn{5}{c}{ Parameter } \\
Countries & $\mathbf{a}$ & $\mathbf{b}$ & $\boldsymbol{\mu}$ & \multicolumn{1}{c}{$\mathbf{S}_{\boldsymbol{1}}$} & \multicolumn{1}{c}{$\mathbf{S}_{\mathbf{2}}$} \\
\hline Cameroon & 0.003 & 0.242 & 23.657 & 9.855 & 19.928 \\
Ethiopia & 0.008 & 0.247 & 25.485 & 10.338 & 20.066 \\
Nigeria & 0.008 & 0.267 & 27.553 & 13.746 & 16.097 \\
South Africa & -0.001 & 0.106 & 23.702 & 9.512 & 19.889 \\
\hline
\end{tabular}




\section{Appendix B}

Figure 2: Empirical and estimated ASFR for Cameroon (2004)

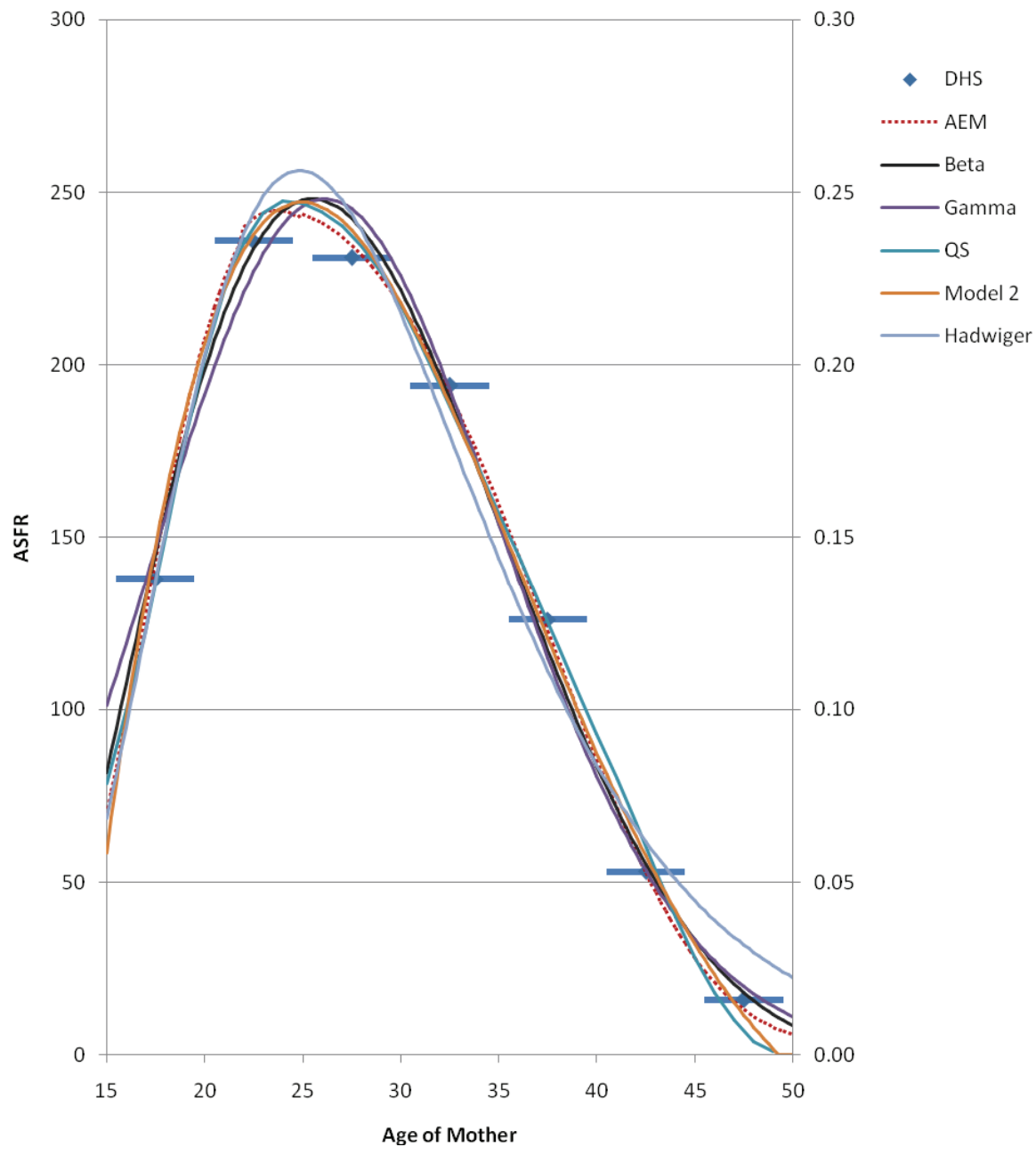


Figure 3: $\quad$ Empirical and estimated ASFR for Nigeria (2003)

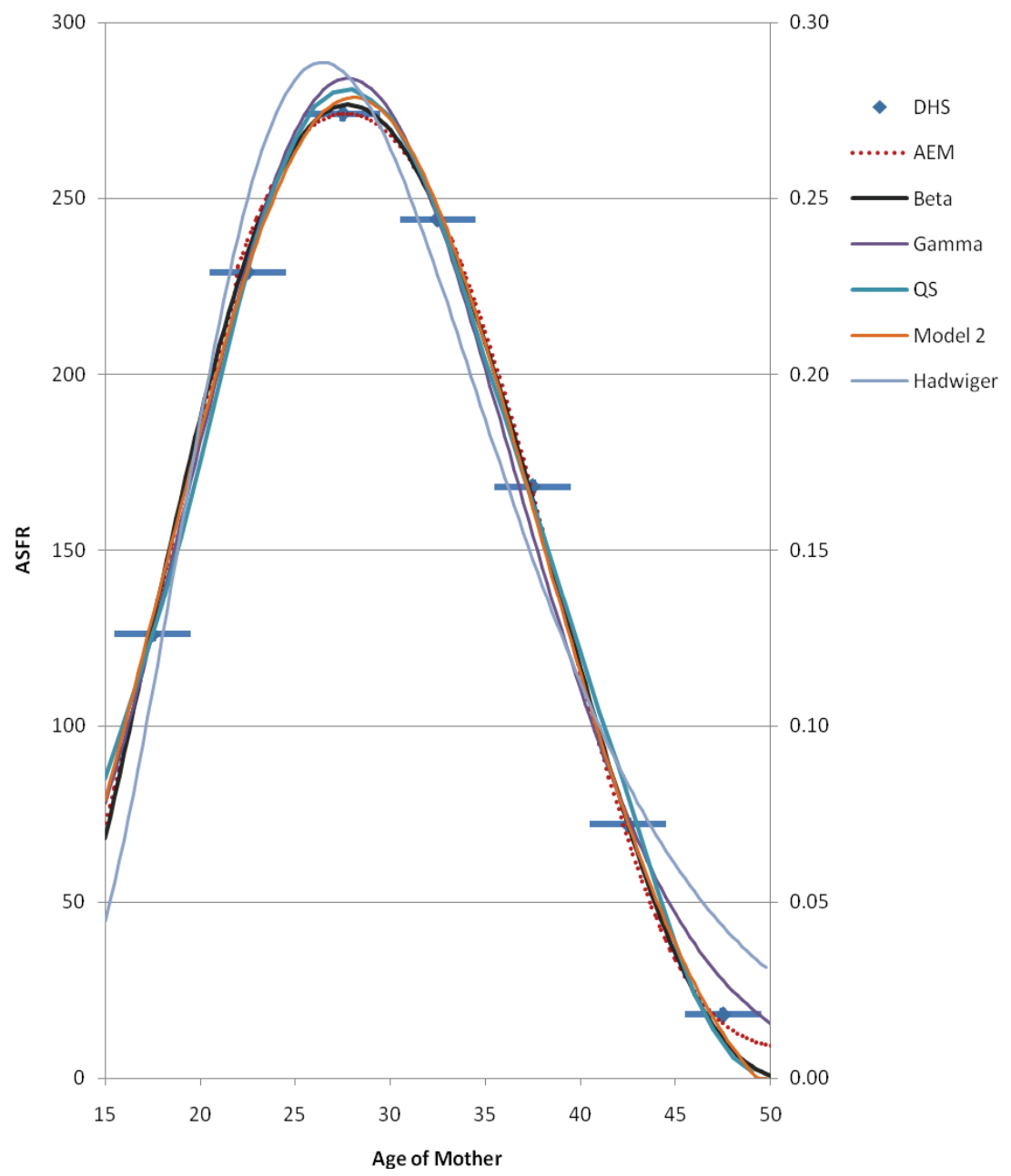


Figure 4: Empirical and estimated ASFR for South Africa (2003)

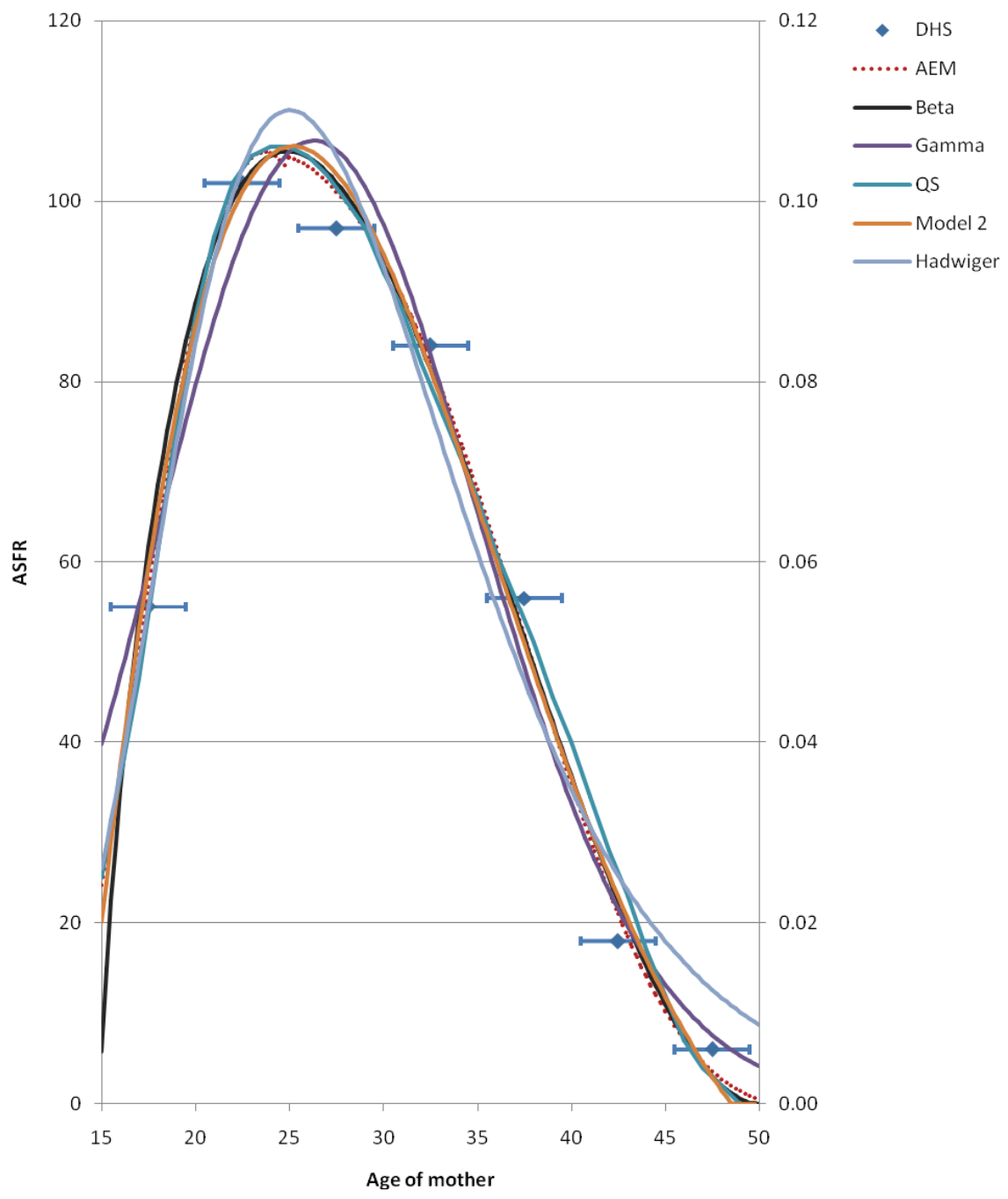


Figure 5: Relationship between modal fertility rate and parameter $b$ of the AEM

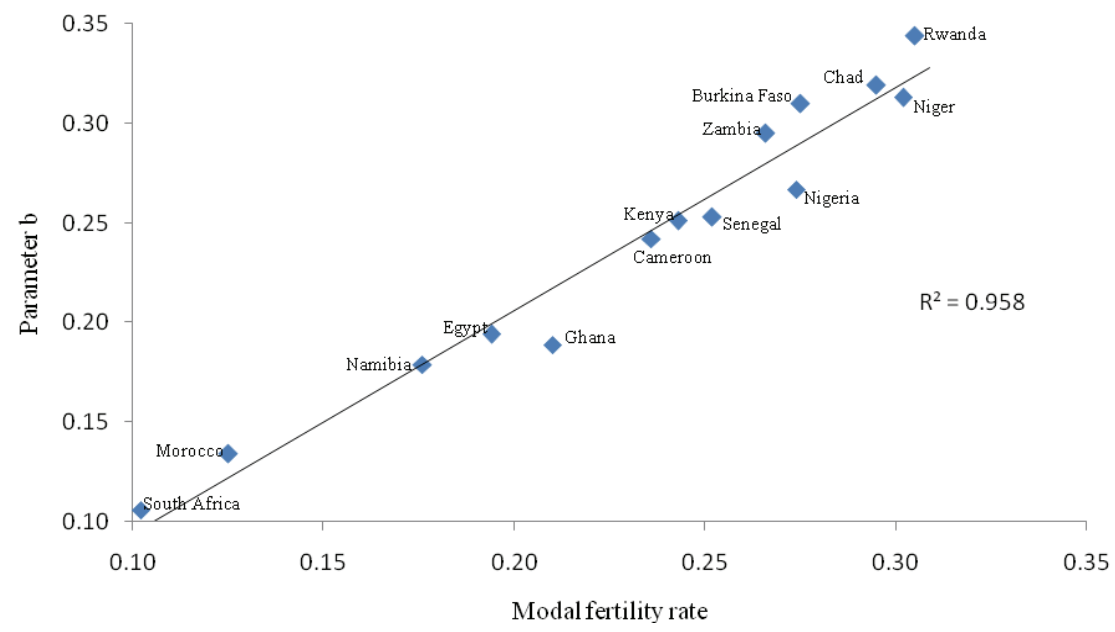

Figure 6: Relationship between fertility level at the age group 45-49 of the mother and parameter $a$ of the AEM

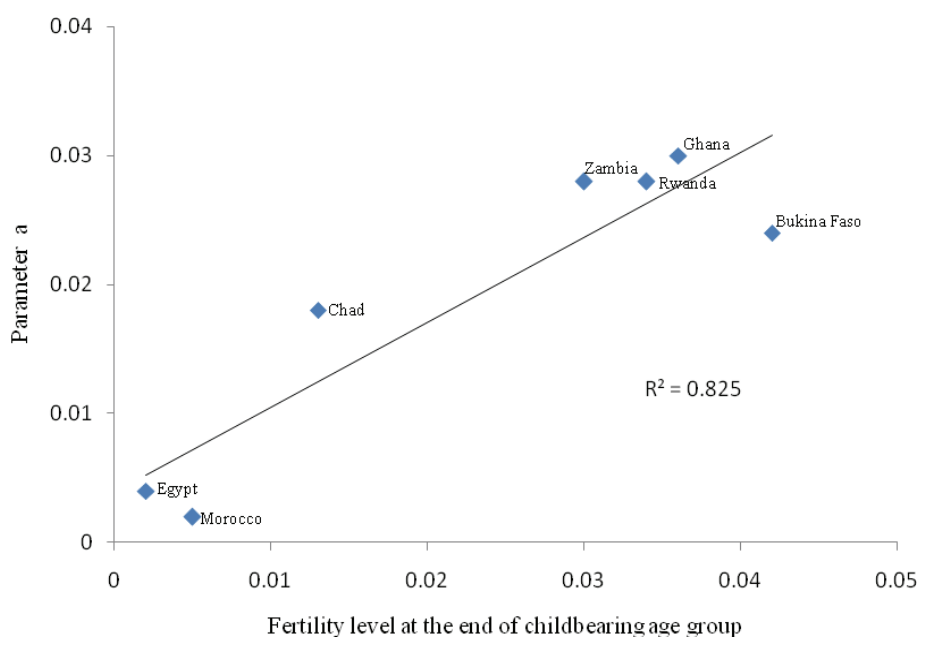

